\title{
EVALUATION OF EUSCREEN - VISION SCREENING - DATA
}

\author{
Oana Teodosescu, Mihai Mara, Cristina Vladutiu, Simona Cainap, Daniela Rajka
}

UMF Iuliu Hatieganu, Cluj-Napoca

\begin{abstract}
AIMS: The EUSCREEN study aims to compare vision and hearing screening programs for children in all EU states by using a cost-optimization model. A model-developed vision screening program has been tested in the county of Cluj in Romania. The ultimate goal would be to implement a nationwide vision screening program designed to detect visual deficiencies in children.

METHODS: 98 nurses trained by UMF Cluj examined children aged 4 and 5 in public and private kindergartens and in rural family doctors' offices in 2018 and 2019: 6951 children were examined in Cluj-Napoca, 2677 children in the other 5 municipalities in the county and 3241 children were tested in the rural areas.

RESULTS: In the city of Cluj-Napoca 49 nurses from public kindergartens and 4 nurses and 1 doctor from the private kindergartens were enrolled in the project. They examined 6951 children $(74 \%$ of the eligible). In the five smaller cities 23 nurses examined 2677 children ( $76 \%$ of the eligible).In the rural areas 3241 children ( $47 \%$ of the eligible) were examined by 33 screeners: 2 travelling nurses, 2 family doctors, 29 family doctors nurses.

12080 children were first examined using the E charts while 789 children were examined using the Lea charts. On the second examination 125 children were examined using the E charts and 210 using the Lea charts, and on the third examination 24 children were examined using only Lea charts.
\end{abstract}

From the 12869 examined children 11328 children had a normal visual acuity for their age, while 1507 children were referred for an ophthalmologic examination: 946 children from Cluj-Napoca (13.60\%), 253 children $(9,45 \%)$ from the other five cities in the country and 308 children $(9.5 \%)$ from rural areas. Only 419 results were collected from the ophthalmologists: $280(30 \%)$ reports of children from Cluj-Napoca, 88 (35\%) forms from children in the small cities, and only $51(17 \%)$ reports of children from the rural areas.

In 212 out of the total 419 children examined by ophthalmologists (representing 50.59\%) a visual acuity disorder was documented. 201 children $(47.97 \%)$ had a visual acuity within the normal range for the age. The leading causes supposedly responsible for the reduction in visual acuity were: refractive errors (194), strabismus (19), functional amblyopia (38) and organic causes (3). Strabismus was detected in a number of 19 children $(4,53 \%)$.

Optical correction was prescribed in 171 cases, while 37 patients were also recommended occlusion therapy. According to the ophthalmological reports, 234 children required a follow-up at a variable interval (ranging between 2 months and 1year)

CONCLUSIONS: The high number of confirmed cases of visual acuity disorders, the important number of glasses prescriptions and the detection of cases that require occlusion treatment emphasizes the value of visual screening.

KEY-WORDS: visual screening, children

\section{Acknowledgement}

This article is part of project EUSCREEN - received funding from the European Union's Horizon 2020 research and innovation programme under Grant Agreement No 733352

\footnotetext{
* Author correspondent: Oana Teodosescu, UMF Iuliu Haţieganu, Cluj-Napoca, e-mail: teodosescuoana@, yahoo.com

Article received: 28.03 .2021 , accepted: 7.09.2021, published: 15.10 .2021

Cite: Teodosescu O, Mara M, Vladutiu C, Cainap S, Rajka D. Evaluation of EUSCREEN project - vision screening - data. Journal of School and University Medicine 2021;8(3):36-42
} 


\section{Introduction}

Amblyopia is a relatively common neurodevelopmental abnormality, established in early childhood, that results in physiological alterations in the visual pathways and impaired vision in one eye, less commonly in both [1]. Current studies have reported a $1.6 \%$ prevalence of amblyopia among preschoolers in the US [2,3]. As it is, uncorrected visual impairment in childhood is associated with reduced academic performance and psychological stress [4]. Furthermore, it is worth mentioning that amblyopia also carries an increased lifetime risk (at least three times that of the general population) of serious vision loss of the fellow eye, which was estimated at least $1.2 \%$ [5]. However, if detected early and appropriately treated, amblyopia is reversible.

Pediatric vision screening programs generally stress upon early detection and facilitation of appropriate visual rehabilitation to prevent or minimize visual disability [6]. A recent review of the pediatric vision screening program in 18 countries across five continents concluded that the implementation of a vision screening program is diverse within countries preceded by limited resources issues [7]. At this time, in Romania there is no regulated national preschool visual screening system.

EUSCREEN, or else, "Implementation of optimized childhood vision and hearing screening programs in middle-income countries in Europe", is a 4 -year multicenter European project funded by the HORIZON 2020 program which aims to compare vision and hearing screening programs for children in all EU states by using a cost-optimization model [8]. Accordingly, model-developed screening programs have been tested in the county of Cluj in Romania for vision, and in three counties in Albania for hearing screening.

The pilot study in the county of Cluj was conducted over a 2-year period: 2018 and 2019. Visual screening was coordinated and supervised by the "Iuliu Hațieganu" University of Medicine in Cluj-Napoca and the Department of Social and Medical Assistance (DASM), official partners in the EUscreen project.

The ultimate goal would be to implement a nationwide vision screening program designed to detect visual deficiencies in children. Choosing the perfect target group for the screening was the subject of much controversy. Suitably, the child should be old enough to cooperate but in the same time young enough for the likely amblyopia treatment to be effective. Telleman et al. 2019 determined that "measurement of VA at the age of 36 months cannot be recommended as a screening test in the general population" [9]. Traditionally, the treatment of amblyopia commenced prior the age of 7 has shown significant success rates and the younger the child is when treatment commences, the more rapid the response to treatment and the better the visual outcome [10]. On the other hand, one study revealed that $74 \%$ of children aged $7-12$ years treated with patching, and $80 \%$ treated with atropine have some degree of residual amblyopia on long-term follow-up [11]. Wothin the Euscreen project, it was eventually established that the eligible age of the children to be included in the study would be 4 and 5 years.

Due to a shortage of pediatric ophthalmologists and to the limited financial resources of the program, nurses, who were already involved in preventive and health promotion activities, were considered to be the most appropriate healthcare providers to perform the actual screening. Because in Romania the distribution of school dispensaries is not uniform at the level of the counties, with $95 \%$ of them being in the urban environment [12], visual acuity was measured in project by the nurses in the kindergardens in the city of ClujNapoca and in the other five towns/municipalities (Turda, Câmpia-Turzii, Huedin, Dej, Gherla), respectively the family doctors or their nurse practitioners in the rural areas in the county. A comprehensive literature review of the pediatric vision screening program in 18 countries across five continents similarly revealed that non-eyecare practitioners, including trained staff, nurses, and even parents, were involved in the visual screening in $94 \%$ of the countries [7].

\section{Materials and methods}

The medical personnel involved in the screening were required to attend a mandatory two-day training session organized at the University of Medicine and Pharmacy Cluj-Napoca prior to the commencement of the screening. The structure of these courses included an initial overview of the Euscreen project and an induction on visual acuity screening and visual 
disorders, followed by a detailed exemplification of the visual acuity measurement technique and a practical workshop in which every partaker had the opportunity to perform a visual acuity test under the direct supervision of a pediatric ophthalmologist [13]. At the end of each course, the participants were expected to pass a multiple-choice test. The UMF team organized a total of five training sessions.

154 nurses attended the course, 98 of whom decided to enroll in the project.

Both the preschoolers from the public kindergartens and those from the private kindergartens were included in the EUSCREEN project. During the two years of the implementation of the vision screening in urban areas, the nurses in kindergartens screened a total of 9710 children aged between 4 and 6 years: 6951 children were examined in Cluj-Napoca and the remaining 2677 children in the other 5 municipalities in the county. Additional 3241 children were tested in the rural areas.

\section{Results and discussions}

Out of the 72 nurses from the kindergartens in Cluj-Napoca that attended the training course, only $49(68,05 \%)$ agreed to take part in the screening. Additionally, 4 nurses and 1 doctor from the private kindergartens in Cluj-Napoca were enrolled in the project; they examined children from several private kindergartens in the city. Similarly, 31 nurses in the 5 municipalities followed the course and $23(74,19 \%)$ enrolled in the Euscreen project. The lowest percentage was recorded in the rural areas, where only 26 out of the $51(50,98 \%)$ trained general practitioners and nurses chose to sign up for the visual acuity screening.

Prior to the introduction of the EUSCREEN project, some of the nurses and doctors in the kindergartens usually included the visual acuity testing in the routine health check-up; however, this was not done consistently and systematically and not every kindergarten owned a visual acuity eye chart. According to one of our previous research, $64.60 \%$ of the medical staff who attended the training course (115 out of 178) acknowledged not having screened vision acuity in children before [13]. Hence, some of the participants to the course might not have been willing to take up further responsibility or did not find the financial reward substantial enough.

\begin{tabular}{|l|c|c|}
\hline \multicolumn{1}{|c|}{ Nurses } & Followed course & Screened children \\
\hline $\begin{array}{l}\text { Cluj- } \\
\text { Napoca }\end{array}$ & 72 & 49 \\
\hline Small cities & 31 & 23 \\
\hline Rural areas & 51 & 26 \\
\hline
\end{tabular}

Table 1: nurses who followed the course and nurses who screened children

During the two years of the implementation of the vision screening in urban areas, the nurses in kindergartens screened a total of 9710 children aged between 4 and 6 years: 6951 ( $74 \%$ of the eligible) children were examined in Cluj-Napoca and the remaining 2677 ( $76 \%$ of the total eligible) children in the other 5 municipalities in the county.

In Cluj county approximately $35 \%$ of the children eligible for visual acuity measurement in the EUSCREEN project (four- and five-year-olds, meaning all children born in Cluj County in 2013, 2014 and 2015) live in the rural area. This is a total of 6877 children. Considering the fact that the school medicine network is present in only 3 of the 74 communes of the Cluj county, rural screening was planned to take place in the family doctors' offices.

In the two years of the Euscreen project, 3241 rural children ( $47 \%$ of the eligible preschoolers) were examined by 33 screeners: 2 travelling screening nurses, 2 family doctors and 29 nurses ( 5 of whom also examined children in the surrounding communes, and one of them became, towards the end of the project, the third travelling screening nurse). In 2018, 1100 children were examined, and in 2019, 2141 children were examined.

The percentage of screened children, fluctuating from $47 \%$ in the rural areas to $74-76 \%$ in the urban areas resembles the overall results of a recently published survey on the likelihood of vision testing of children aged 3-5 years in the United States. The latter study disclosed that parent-reported vision testing rates by state ranged from $41 \%$ to $84 \%$ [14]. Furthermore, the same study stressed upon the fact that the requirement of a state-level school vision testing was associated with an increased parent-reported vision testing in children 3-5 years of age [14]. 
This information could well relate to one of the findings in our previously published analysis on the main reasons why the study did not include a higher number of preschoolers, among which the participants to the survey mentioned lack of parents' consent, their lack of time or even lack of interest as long as it was not a mandatory assessment [15].

\begin{tabular}{|l|c|c|c|}
\hline \multicolumn{1}{|c|}{ Area } & Total eligible (3 birth years) & Screened & Percentage \\
\hline Cluj-Napoca & 9382 & 6951 & $74 \%$ \\
\hline Small cities & 3495 & 2677 & $76 \%$ \\
\hline Rural areas & 6877 & 3241 & $47 \%$ \\
\hline Total & $\mathbf{1 9 7 5 4}$ & $\mathbf{1 2 8 6 9}$ & $\mathbf{6 5 \%}$ \\
\hline
\end{tabular}

Table 2: eligible children and screened children

Following the screening, 946 children in ClujNapoca were referred to an ophthalmological test, that is $13.60 \%$ of the number of children that had been tested. In the other 5 municipalities in the county, 253 $(9,45 \%)$ children were referred to the ophthalmologist. A total of 308 out of 3241 screened children $(9.5 \%)$ from rural areas received the recommendation to be examined by an ophthalmologist in a city.

These results are significantly lower than the ones reported by a study in Baltimore City Public Schools according to which $34 \%$ of students failed vision screening, with children in kindergarten and 3rd grade and higher being statistically more likely to fail screening than those in 1st grade [16]. A different study carried out in Wayne County, Michigan in 2016 showed that of 56,572 children screened, 4,689 $(8.3 \%)$ failed [17], hence the number of children that required follow-up examination after a failed screening is closer to the one in the Cluj county rural areas.

Only 280 (30\%) eye examination reports were returned to the nurses in the city, and 88 (35\%) forms filled out by an ophthalmologist were received in the small municipalities. The rates are even lower in the rural areas, where only $17 \%$ of the referred children actually turned in their ophthalmological reports. Similar studies in literature usually report higher follow-up reports. Likewise, Donahue and colleagues' study of 15,000 preschool children found that about $50 \%$ of referred children had documented follow-up care [18]. A previously mentioned study showed that $47.6 \%$ of the Wayne County school-age children had the required follow-up examination within 16 weeks of the failed screening [17].

\begin{tabular}{|l|c|c|c|}
\hline & Referrals & F5 in database & \% F5 in database \\
\hline Cluj-Napoca & 946 & 280 & $30 \%$ \\
\hline Small cities & 253 & 88 & $35 \%$ \\
\hline Rural & 308 & 51 & $17 \%$ \\
\hline Total & $\mathbf{1 5 0 7}$ & $\mathbf{4 1 9}$ & $\mathbf{2 8 \%}$ \\
\hline
\end{tabular}

Table 3: referrals and forms 5 entered in the project database

An important issue of examining children in rural areas is that of referring children with visual impairments to the ophthalmologist and collecting the results of the ophthalmological examination. In the rural areas there are no ophthalmologists, meaning parents from rural areas had to take their child to a city for an ophthalmological assessment and repeat visits for treatment of amblyopia. Similarly, the University of
Southern California Los Angeles Preschool Vision Program initially reported an overall examination rate of $64.8 \%$ among 1,554 preschool children who met referral criteria from screening tests and noted a higher examination rate $(70.8 \%)$ among children who had an appointment in their own school than having to go to a different school (53.9\%) [19]. 
Almost twice as many ophthalmological reports from Cluj-Napoca as from the rural areas were entered in the database. A possible explanation for a very small number of results from the ophthalmologist is the lack of financial resources of the family for travelling to the city for a doctor appointment, but also a lack of understanding the detected health problem. It is also possible that some parents of visually impaired children may no longer have considered it necessary to transmit the result of the examination to the family doctor or to the Euscreen team. Kemper and colleagues reported that the rate of follow-up eye care was much greater when parents were contacted to verify follow-up [20].

From the total of 12869 examined children a total of 12500 were examined only once by the nurses before reaching a conclusion (either Examination OK or Referral to an ophthalmologist). 369 children needed a second examination, but only 341 of them were examined the second time. From these 341 children: 311 cases were concluded during the second examination. 30 children needed a third retesting, as per screening protocol, but only 24 children were screened a third time. A total of 34 children that needed retesting weren't retested.

\begin{tabular}{|l|c|c|c|}
\hline & One examination & Two examinations & Three examinations \\
\hline Cluj-Napoca & 6867 & 44 & - \\
\hline Small cities & 2591 & 95 & - \\
\hline Rural areas & 3042 & 172 & 24 \\
\hline TOTAL & 12500 & 311 & 24 \\
\hline
\end{tabular}

Table 4: number of examinations needed for a result (either Examination OK or Referral to an ophthalmologist)

12080 children were first examined using the E charts while 789 children were examined using the Lea charts (522 in Cluj-Napoca, 30 in small cities, 237 in rural area), On the second examination 125 children were examined using the E charts and 210 using the Lea charts, and on the third examination 24 children were examined using only Lea charts. Indeed, Lea symbols, consisting of a set of four symbol optotypes, are especially helpful because each optotype blurs similarly as the child is presented with smaller symbols, increasing the reliability that individual symbols will be identified [21]

From the 12869 examined children 11328 children had a normal visual acuity for their age, while 1507 children were referred for an ophthalmologic examination. The project team managed to collect only 419 results from the ophthalmologists (roughly 28\%) (Table 5).

\begin{tabular}{lcccc}
\hline & Examined & OK & Referred & $\begin{array}{c}\text { Results from } \\
\text { ophthalmologist }\end{array}$ \\
\hline Cluj-Napoca & 6951 & 5985 & 946 & 280 \\
\hline Small cities & 2677 & 2412 & 253 & 88 \\
\hline Rural & 3241 & 2931 & 308 & 51 \\
\hline Total & $\mathbf{1 2 8 6 9}$ & $\mathbf{1 1 3 2 8}$ & $\mathbf{1 5 0 7}$ & $\mathbf{4 1 9}$ \\
\hline
\end{tabular}

Table 5. Number of examined and referred childrens

From the total number of 1507 of children referred for ophthalmological assessment a merely low percentage $(27,8 \%)$ have returned the F5 forms (419 children). The rest of them, meaning $1088(72,2 \%)$ children, may be considered lost to the follow up. The main reasons why this happened were investigated by the UMF team and recorded in the previous chapter.
In 212 out of the total 419 children examined (representing 50.59\%) a decreased VA, that is to say, a visual acuity disorder, was documented. 201 children $(47.97 \%)$ had a visual acuity within the normal range for the age. In six cases $(1,43 \%)$ the $\mathrm{F} 5$ forms provided could not be interpreted due to unavailability of data. 
A study conducted in Nobeoka City, Japan revealed that out of 3,303 eligible children, 2,161 (65.4\%) underwent secondary screening [22]. Other studies have shown a significantly lower false positive rate of $13 \%$ [23]

The leading causes supposedly responsible for the reduction in visual acuity were: refractive errors (194), strabismus (19), functional amblyopia (38) and organic causes (3). One or more causes of reduced visual acuity were present in each of the confirmed cases.

$91,5 \%$ of the children presenting with a reduced visual acuity or $46,3 \%$ of the referred children exhibited an associated refractive error. Other studies indicated the presence of a refractive error in 44\% [23] or $33 \%$ [24] of cases. The analysis of the refraction numbers revealed myopia in 19 children, hyperopia in 28 and astigmatism in 100 children; anisometropia was noted in 47 preschoolers. In the absence of cycloplegia in all children, the inclusion in a certain of refractive error category was correlated with the level of the visual acuity.

Strabismus was detected in a number of 19 children $(4,53 \%)$. Other studies signaled a misalignment of the visual axis in 3\% [22] or 13\% [23] of cases.

The category of functional amblyopia included children with strabismus, anisometropia or both in which the glasses did not fully correct visual acuity. The $38(9,06 \%)$ cases of functional amblyopia were separated in strabismic (4 cases), anisometropic (26 cases), isoametropic (1case) and mixed amblyopia (7). Amblyopia was present in $16 \%$ [22] or $30 \%$ [23] of cases according to other studies.

Associated ophthalmological conditions were described in 3 children: chorioretinal scars, corneal scarring and congenital cataract. The Walsall study also come across a wide range of conditions, such as cataract, ptosis, nystagmus, corneal scarring, Duane retraction syndrome, unexplained vision loss, and latent strabismus [23].

Optical correction was prescribed in 171 cases, while 37 patients were also recommended occlusion therapy. According to the ophthalmological reports, 234 children required a follow-up at a variable interval (ranging between 2 months and 1year) (Table 6).

\begin{tabular}{lc}
\hline Optical correction & 171 \\
\hline Occlusion therapy & 37 \\
\hline $\begin{array}{l}\text { Follow-up is recommended } \\
\text { (in 2-12 months) }\end{array}$ & 234 \\
\hline
\end{tabular}

Table 6. Measures recommended by ophthalmologists

The majority of the ophthalmologists (356) use a decimal visual acuity measurement system, while 37 use a LogMAR eye test; in 29 cases the value of the visual acuity was recorded in both decimal and LogMar systems.

The distance between the child and the eye chart also varied: 33 children were examined at a distance of 3 meters, 64 children at 4 meters, 122 children at 5 meters, while for 201 children the distance was not mentioned.

The decimal system was used for the visual acuity for 356 children, the logarithmic system was used for 37 children (for 29 children both systems were used), while for 55 children the visual acuity was not mentioned at all.

\section{Conclusions}

The high number of confirmed cases of visual acuity disorders (212 cases out of 419 ophthalmologist' results, 50.6\%), the important number of glasses prescriptions (171 prescriptions from 419 results, $40.8 \%$ ) and the detection of cases that require occlusion treatment emphasizes the value of visual screening. 


\section{Bibliography}

1. Levi, D. M. Rethinking amblyopia 2020. Vision Research. 2020 (176):118-129.

2. USPST Force, Grossman DC, Curry SJ, et al. Vision screening in children aged 6 months to 5 years: US preventive services task force recommendation statement JAMA. 2017;318(9):836-844

3. Shakarchi AF, Collins ME. Referral to community care from school-based eye care programs in the United States. Surv Ophthalmol 2019(64):858-867

4. Evans JR, Morjaria P, Powell C. Vision screening for correctable visual acuity deficits in school-age children and adolescents. Cochrane Database Syst Rev.2018;2:CD005023

5. Rahi J, Logan S, Timms C, Russell-Eggitt I, Taylor D (2002) Risk, causes, and outcomes of visual impairment after loss of vision in the non-amblyopic eye: a population-based study. Lancet 360:597-602

6. Mathers M, Keyes M, Wright M. A review of the evidence on the effectiveness of children's vision screening. Child Care Health Dev. 2010;36(6):756-780

7. Chen AI, Bakar NFA, Arthur P. Comparison of the pediatric vision screening program in 18 countries across five continents. J Curr Ophthalmol 2019 Sep 3;31(4):357-365

8. Simonsz HJ, Carlton J, Griffith H, et al. EUSCREEN study, stage 1: data collection on vision and hearing screening programs in 40 European countries and Turkey, Israel, Russia, Malawi, Rwanda, Suth-Africa and India. Invest Ophthalmol Vis Sci. 2019;60(9):3.

9. Telleman MAJ, Sloot F, Benjamins J \& Simonsz HJ. High rate of failed visual-acuity measurements with the Amsterdam Picture Chart in screening at the age of 36 months. Acta Ophthalmol 2019: 97(1): 24-28

10. Webber, A. L. (2007). Amblyopia treatment: an evidence-based approach to maximising treatment outcome. Clin Exp Optom 2007; 90: 4: 250-257

11. Scheiman MM, Hertle RW, Kraker RT, et al . Pediatric Eye Disease Investigator Group. Patching vs atropine to treat amblyopia in children aged 7 to 12 years: a randomized trial. Arch Ophthalmol 2008;126:1634-42.doi:10.1001/ archophthalmol.2008.107

12. Pop TL, Burlea M, Falup-Pecurariu O, Borzan C, Gabor-Harosa F, Herdea V, Pop CF, Rajka D, Ognean ML, Căinap SS. Overview of the pediatric healthcare system in Romania. Turk Pediatri Ars. 2020 Sep 1;55(Suppl 1):69-84. doi: 10.14744/TurkPediatriArs.2020.77775. PMID: 32963483; PMCID: PMC7488180.
13. Vlăduţiu C, Căinap S, Teodosescu O, Ursu RM, Sevan SA, Rajka D, Mara M. Previous expertise and initial attitude towards vision screening in health care professionals enrolled in EUSCREEN project. Journal of School and University Medicine 2020;7(1-2):12-17

14. Lillvis, J. H., Lillvis, D. F., Towle-Miller, L. M., Wilding, G. E., \& Kuo, D. Z. (2020). Association of state vision screening requirements with parent-reported vision testing in young children. J AAPOS 2020;24(5): 291-291

15. Teodosescu O, Mara M, Vlăduţiu C, Căinap S, Rajka D. Final expertise and attitude towards vision screening in health care professionals enrolled in the euscreen project. Journal of School and University Medicine 2020;7(4):17-24

16. Milante R, Guo X, Neitzel AJ, Kretz AM et al. Analysis of vision screening failures in a school-based vision program (2016-19). JAAPOS 2021Feb 16;S1091-8531(21)00025-2

17. Musch, D. C., Andrews, C., Schumann, R., \& Baker, J. A community-based effort to increase the rate of follow-up eye examinations of school-age children who fail vision screening: a randomized clinical trial. J AAPOS 2020;24:98.e1-4

18. Donahue SP, Johnson TM, Leonard-Martin TC. Screening for amblyogenic factors using a volunteer lay network and the MTI photoscreener. Initial results from 15,000 preschool children in a statewide effort. Ophthalmology 2000;107:1637-44

19. Mehravaran S, Duarte PB, Brown SI, Mondino BJ, Hendler K, Coleman AL. The UCLA Preschool Vision Program, 2012-2013. J AAPOS 2016;20:63-7

20. Kemper AR, Fant KE, Bruckman D, Clark SJ. Hearing and vision screening program for school-aged children. Am J Prev Med 2004;26:141-6

21. Cyert L, Schmidt P, Maguire M, et al. Vision in Preschoolers (VIP) Study Group. Threshold visual acuity testing of preschool children using the crowded HOTV and Lea Symbols acuity tests. J AAPOS 2003;7(6):396-9

22. Tamura S, Yoshitake S, Okano M et al. Benefits of consulting a certified orthoptist in a pediatric vision screening program J AAPOS 2020;24(6):371-374

23. Hu VH, Starling A, Baynham SN, Wager H, ShunShin GA. Accuracy of referrals from an orthoptic vision screening program for 3- to 4- year-old preschool children. J AAPOS 2012;16:49-52

24. Clarke MP, Wright CM, Hrisos S, Anderson JD, Henderson J, Richardson SR. Randomised controlled trial of treatment of unilateral visual impairment detected at preschool vision screening. BMJ 2003;327:1251 